Vadim Yu. Rumiantsev ${ }^{1 *}$, Alexey A. Golubinsky ${ }^{2}$, Mikhail S. Soldatov ${ }^{1}$, Alexandre Husson ${ }^{3}$, Dmitry A. Khitrov ${ }^{4}$

1. Department of Biogeography, Faculty of Geography, Lomonosov Moscow State University; Leninskiye Gory, 1, 119234, Moscow, Russia; tel.: 8 (495) 9394717, fax: 8 (495) 9328836

2. The Russian State Archive of Ancient Documents (RSAAD). Faculty of History, Lomonosov Moscow State University, Lomonosovsky prospect, 27-4, 119992, Moscow, Russia; tel. 8 (495) 9395440, fax 8 (495) 9392390

3. University Paris I Panthŭon-Sorbonne, France. Faculty of History, Lomonosov Moscow State University, Lomonosovsky prospect, 27-4, 119992, Moscow, Russia; tel. 8 (495) 9395440, fax 8 (495) 9392390

4. Department of Russian History to the beginning of the XIX century, Faculty of History, Lomonosov Moscow State University, Lomonosovsky prospect, 27-4, 119992, Moscow, Russia; tel. 8 (495) 9395440, fax 8 (495) 9392390

* Corresponding author. e-mail: vyurum@biogeo.ru

\title{
CHANGES OF MAMMAL BIODIVERSITY IN THE EUROPEAN RUSSIA (THE END OF THE XVIII CENTURY - XXI CENTURY)
}

\begin{abstract}
The paper investigates the data on the fauna of the European Russia at the end of the XVIII century, contained in the materials of the General Land Survey, in comparison with contemporary data. The distribution ranges of the majority of large mammals observed in the study area two centuries ago, have not changed significantly, but the biological diversity has increased due to the emergence of new species.
\end{abstract}

KEY WORDS: General Land Survey, biogeographical and historical research, mammals, human impact on nature.

\section{INTRODUCTION AND BACKGROUND}

One of the key processes of the Russian history of the XVI-XIX centuries is its fast territorial expansion, which has helped to partially offset the adverse natural impact of the country's historic center on the agriculture [Milov, 2006]. This feature dramatically distinguishes Russian history in the early modern period from the history of other European countries, and makes it very interesting from the point of view of the study of how the human impact changed the environment. Rapid population growth, while maintaining almost exclusively agrarian nature of the economy, was secured by involving in the agricultural use a vast lands and developing new agricultural areas, especially in the South and East of the country. Since the beginning of the XVII century and until the end of the XVIII century, the total area of arable land increased almost 4 times [Vodarskii, 1988] and this process continued into the next century. The main growth occurred in the European part of the country where the boundaries of agricultural settlement moved many hundreds of kilometers to the South and East.

The question of how it affected the composition of the fauna has not been previously discussed by the historians of Russia, although similar works in other regions of the world exist and constitute a rapidly developing interdisciplinary research direction of environmental history [Rackham, 
2001; Extinctions ..., 2010; Ouchley, 2010, etc.].

In the public opinion, there is a fairly stable view that the economic development has led to a sharp decline of biological resources. This idea was carried out in Russian classical literature, for example, in the books by S.T. Aksakov, P.I. Melnikov-Pechersky, N.I. Nekrasov, and I.A. Bunin. Having become quite common, it also had a visible impact on the historians. V.O. Kluchevskii [1987] singled out the massive deforestation and the reduction of the number of wild animals as one of the characteristic features of the process of the Russian colonization. This trend was most fully embodied in the works of M.K. Lubavskii [1996, etc.].

Thus, in the fiction and historical literature the view has formed that the diversity of fauna of the European territory of Russia (hereinafter, ETR) decreased significantly in the XVIII - first half of the XIX centuries, and this was directly linked with the agricultural development of the territory and deforestation. Sources allow testing the validity of this opinion only in part. Only limited information is available on the number of animals that lived on that territory. However, the information on their spatial distribution can be collected from the historical sources from the second half of the XVIII century onwards. In particular, they are systematically presented in the materials of the General Land Survey (hereinafter, GLS).

Started in 1765, the GLS continued for more than 50 years and was the largest archival complex of pre-revolutionary Russia, consisting of more than 1,3 million units. The survey description covers the major part of the ETR, and both the primary documents (field notes of land surveyors and plans of dachas), and the generalized materials of all levels were supplemented with wellpreserved different-scale maps [Golubinsky et al., 2011].

For us, it is particularly important that, in addition to its purely utilitarian task - to distinguish the borders of land holdings, the surveyors had to gather an extensive range of data on each of the surveyed settlements, based on the reports of the local population and on their own observations. In the generalized textual documents of each uezd (district), called "Economic Notes" (hereinafter, EN), in addition to the information on the lands, human settlements and population, the lists of animals, birds and fishes presented it the area were recorded. It is crucial that all this information is gathered with the purposes that we would now identify as scientific, which designates its rather high reliability.

Unfortunately, this "additional" information is not cited in all volumes of the EN. According to the typology of L.V. Milov [1965], it is available in the "Notes to the General Plan", and "Full" and, partly, in the "Cameral" sections of the EN. In the "Concise" and "Pavlovian" sections that make up the majority of the surviving volumes, they are omitted.

Data on the wildlife that we find in the 'Full' section of the EN were collected in the following way. The review of the "internal situation" of each of the landholdings was the task of a Junior Surveyor; this work was considered less important then the survey itself, and, unfortunately, was poorly regulated and almost not documented. We can suggest, however, that the surveyors often received information directly from the local population, according to the so-called "skazki" (reports) of the peasants who served as witnesses during the survey process ("poverennye krestyane"). Unfortunately, only a small number of these interesting documents survived - now, only 400 of them are found [Milov, 1960]. The most detailed type of these documents describes the status of agriculture, forestry etc. "Poverennye" were elected among the most informed and educated peasants, often the headmen of the peasant communities or the bailiffs of local landlords.

The list of wildlife species is given in the 'Full' $\mathrm{EN}$ in the form of the description of each "dacha" (i.e., a landholding); sometimes it 
had a notation: "the animals and birds in the forests, and fish in the rivers are the same as it is written in the description NN". In many cases, in neighboring dachas, these lists coincide. The special research revealed that the differences mainly concern the dachas with few forests when the surveyors excluded the species in the forests from the list. It seems unlikely that the information on the fauna was collected specifically for each of the surveyed landholdings. The "skazki" were composed, as a rule, for the settlements, where the form of the description required the data on crafts, rental obligations, and other information. We can assume that for the non-populated holdings, as well as the small villages, the data from the large neighboring estates were copied. Moreover, as a rule, the number of variants of the list of animals was limited to 3 or 4 per uezd.

This paper is the first in a planned series of studies of the historical changes of the wildlife of the ETR based on the materials of the GLS.

The EN mentions three classes of wildlife: Mammals, or animals (Mammalia), Birds (Aves) and Fishes (Osteichthyes). At the first stage of the work, the mammals were selected as a research object, being a component of the fauna, small enough (in terms of species number) for the convenience of the analysis and important for the humans in different aspects.

The purpose of the study is to estimate the changes in the composition of the mammals fauna of the ETR from the late XVIII century to the present day using the data contained in the EN. The main objectives were:

1. To compile a list of names of animals (the same name in the EN may refer to more than one species), mentioned in the EN, and to evaluate the frequency of occurrence of each of them.

2. To distinguish the animals that particularly attracted the attention of the surveyors, or on the contrary, were ignored by them, despite the obvious importance and to attempt to explain this.

3. To compare the data on the distribution of animals in the EN with the data on their modern distribution and to analyze the revealed changes.

\section{MATERIALS AND METHODS}

This paper explores the information on mammals of the ETR contained in the EN. The provinces of the ETR, where we have complete or nearly complete sets of the EN containing information of interest to us, in the Survey archive in the Russian State Archive of Ancient Documents (RSAAD), Moscow, Russia. For each of them, only part of the existing data is examined here.

Keeping in mind the structure of the data discussed earlier, it seems unnecessary to handle each volume of the EN entirely a representative sample is sufficient for achieving our goal. It is possible that (1) the lists of animals, specific to the uezd, may be incomplete due to the structure of land use in a particular dacha (e.g., the forest species may be excluded in the treeless or sparsely wooded landholdings) and (2) in some cases, the differences in the lists can reflect the real state of affairs - the presence of the species in one part of the uezd and its absence in another. So, a mechanical sample was made: every 25th-35th landholding was selected from each volume of the EN (one record per 25 pages of the manuscript, on average). For small volumes, the number of selected dachas was increased, especially for the uezds with the low fragmentation of land ownership.

Only the populated dachas were selected, with the percentage of forests no lower than the average for the uezd and with the description containing the list of species (the references to other descriptions were excluded). This technique has allowed us to compile a sufficiently complete list of mentioned animals. A control sample, which included 4 randomly selected records from 
each volume, confirmed this - no new species of animals were found.

The sample includes 7 provinces, 33 uezds within them, and 330 dachas. The territorial distribution of the actual material is shown in Fig. 1. Although it doesn't cover the whole territory of the ETR, the sample provides a set of zoogeographic observations, unique for the period of the XVIII - early XIX centuries, regarding its level of detail and territorial coverage. It should be noted that the EN were previously used by the zoologists as a source of data on historical changes of the wildlife of Russia (for example, the works of S.V. Kirikov [1959; 1966, etc.]). However, the data used by them were fragmented in terms of area coverage or set of species analyzed.
Fig. 1 shows that the territory in the sample includes almost all the modern vegetation zones (subzones) within the territories covered by the GLS. Accordingly, the sample should, to some extent, reflect the state of the animal world of the whole ETR (except for the extreme northern and southern areas).

For each dacha, a list of mentioned animals was compiled. It should be mentioned that the transcript was quite accurate, as the names of the species didn't change much since the time of the GLS. On the contrary, for the fishes, the surveyors often use the obsolete local names. It presents some difficulty to identify them, which will be a subject of the further research.

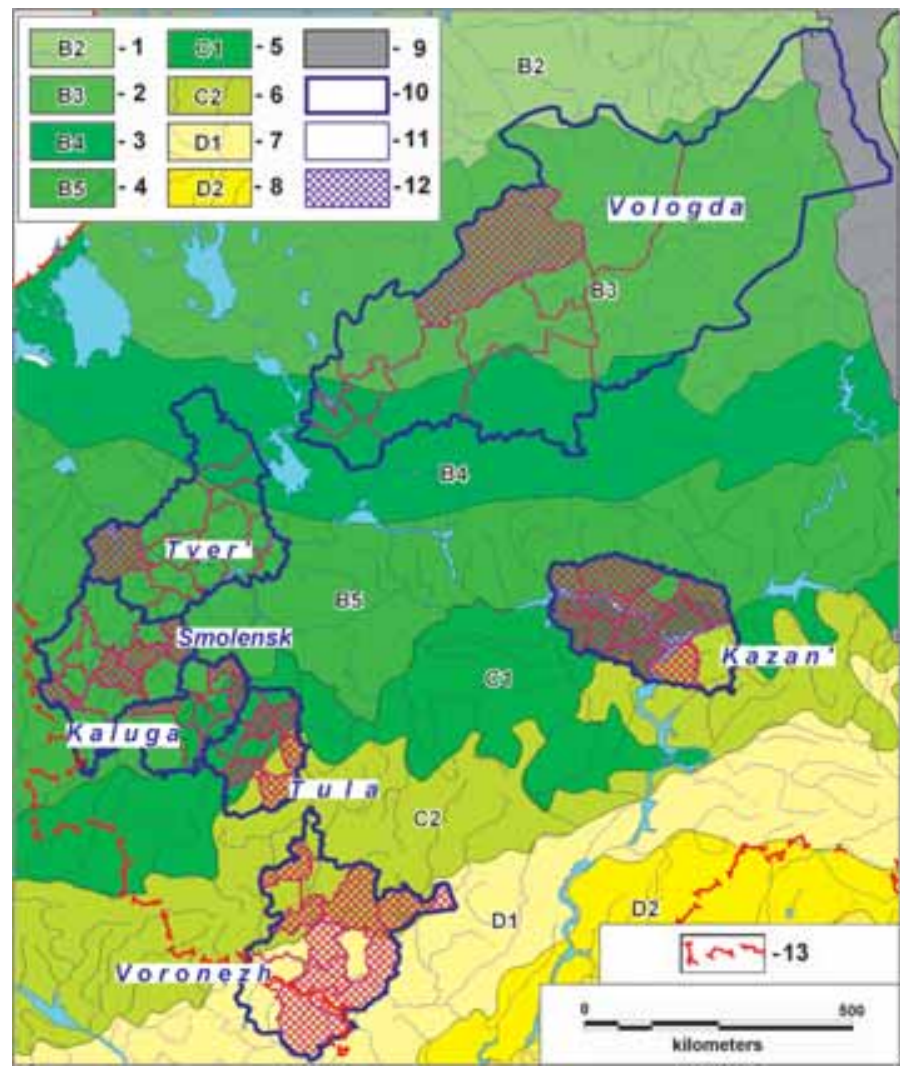

Fig. 1. The studied sample on the map of the modern vegetation zones and subzones of the ETR (Vegetation zones and types ..., 1992, modified).

Vegetation zones and subzones. 1-5 - Taiga zone. Subzones: 1 - northern taiga; 2 - middle taiga; 3 - southern taiga; 4 - sub-taiga (mixed forest); 5-6 - Broad-leaved forest zone. Subzones: 5 - broad-leaved forest; 6 - forest-steppe; 7-8 - Steppe zone. Subzones: 7 - northern (bunch-grass-turf) steppe; 8 - middle (dry) steppe; 9 -Mountain areas; 10 - Borders of provinces included in the sample; 11 - Borders of uezds; 12 - Uezds included in the sample; 13 -Modern border of Russia 
The primary lists of species were aggregated at the uezd, province, and, finally, the whole sample levels. At each stage, the number of mentions of each species was calculated. Finally, the database was compiled containing also modern scientific names of the mentioned animals.

All mentions of each specie were located on the map (at the uezd level) by means of GIS MapInfo Professional. Then, the results were compared with the data on the present territorial distribution of these animals, known from the literature and other sources.

\section{RESULTS AND DISCUSSION}

In the sample, 24 names of mammals are mentioned, belonging to 11 families and 5 orders. Their list, correlated with the modern system of mammals, as well as the frequency of occurrence of each, on the province, uezd, and dacha levels, is shown in Table 1. Here, we must make some clarifications.

1. Currently, more than 250 species of terrestrial mammals live in Russia, belonging to 7-8 orders and more than 30 families [Dinets, Rothschild, 1996, etc.]. More precise calculations are impossible because of the many discrepancies in interpretations of the taxonomic categories. System of the wildlife is ambiguous and is constantly changing, especially in recent decades. We should also take into account that a significant proportion of the species live outside the ETR or in the ETR not covered by the GLS and are not present in our sample.

2. The scientific names (English and Latin) of species and higher taxonomic categories can be different in different sources. Especially it concerns English names, for which, unlike Latin, there are no strict rules of taxonomic nomenclature.

3. The individual names of animals in the sample can match two species - for instance, hares and polecats (see Table. 1). This issue will be discussed in more detail below.
The results of the analysis of occurrence (number of the mentions) of species on the three levels of aggregation are presented in the Fig. 2.

In the Fig. 2, animals can be divided into 5 groups according to the number of references to their names in the sample:

- $\boldsymbol{a}$ - maximum frequency of occurrence. These are: hares (312 references), wolves (226), foxes (186) and squirrels (184) mentioned in all provinces and almost all uezds.

- $\boldsymbol{b}$-relatively high frequency of occurrence. These are stoats (93) and bears (42) mentioned in almost all provinces and more than a half of uezds.

- c - average frequency of occurrence. These are martens (17), marmots (13) and polecats (11) mentioned in 2-3 provinces and 4-7 uezds.

- $\boldsymbol{d}$ - low frequency of occurrence. These are mooses, otters, wild goats, weasels, lynxes, deer, and chipmunks. For each of them, we have 2-5 references in 1-3 provinces and 1-3 uezds.

- $\boldsymbol{e}$ - minimum frequency of occurrence. These are hedgehogs, moles, wolverines, badgers, minks, sousliks, beavers, hamsters. Each of them is mentioned once in the sample, i.e., 1 province and 1 uezd.

Cartographic analysis was used to compare the locations of animals according to the EN to its modern areas within the ETR. The modern boundaries of areas, not defined precisely for all the species, were specified using available literature and, largely, on the basis of materials contained in the database of the Information System "The communities of terrestrial vertebrates of Russia" developed at the Department of Biogeography of the Faculty of Geography, MSU [Rumiantsev, Danilenko, 1998; Danilenko, Rumiantsev, 2008]. 


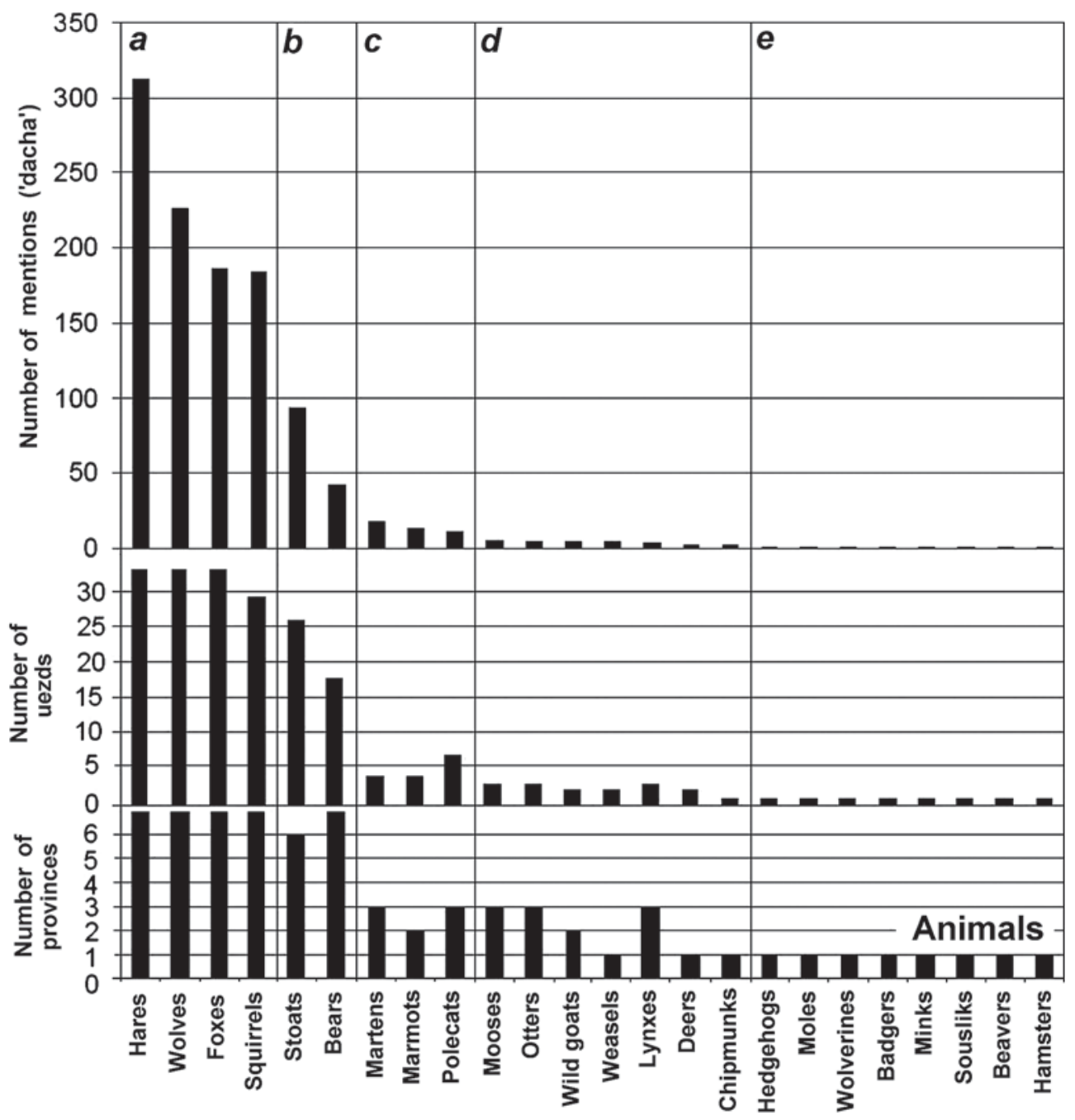

Fig. 2. Frequency of the mentions of animal names in the sample (ranged by the decrease of frequency).

$\boldsymbol{a}$-e - groups of animals conditionally chosen on frequency of their mentions (discussion in the text)

The analysis revealed the fact that almost all of locations of the animals mentioned in the sample are within their modern distribution ranges. The only apparent exception is brown bear. According to the $\mathrm{EN}$, in the period of the GLS its areal extended far to the south beyond the modern southern border of the range (Fig. 3). There are several other, less visible examples - so, lynx is recorded in Masalsk uezd in the Kaluga province. This territory is now nominally included in the range [Bobrov et al., 2008 a.o.], but actually the lynx does not live there, only rare visits are possible.
Two general assumptions are made when discussing the results.

1. If the animal is mentioned in the EN, then it lived in this particular area. Thus, the reliability of the surveyor's observations is postulated and the possibility of errors is ignored.

2. If the animal is NOT mentioned in the EN, this does not mean that it did not live there. It is already obvious that the numerous species, important for the humans, significant and common today, were never or very rare recorded in the EN. 


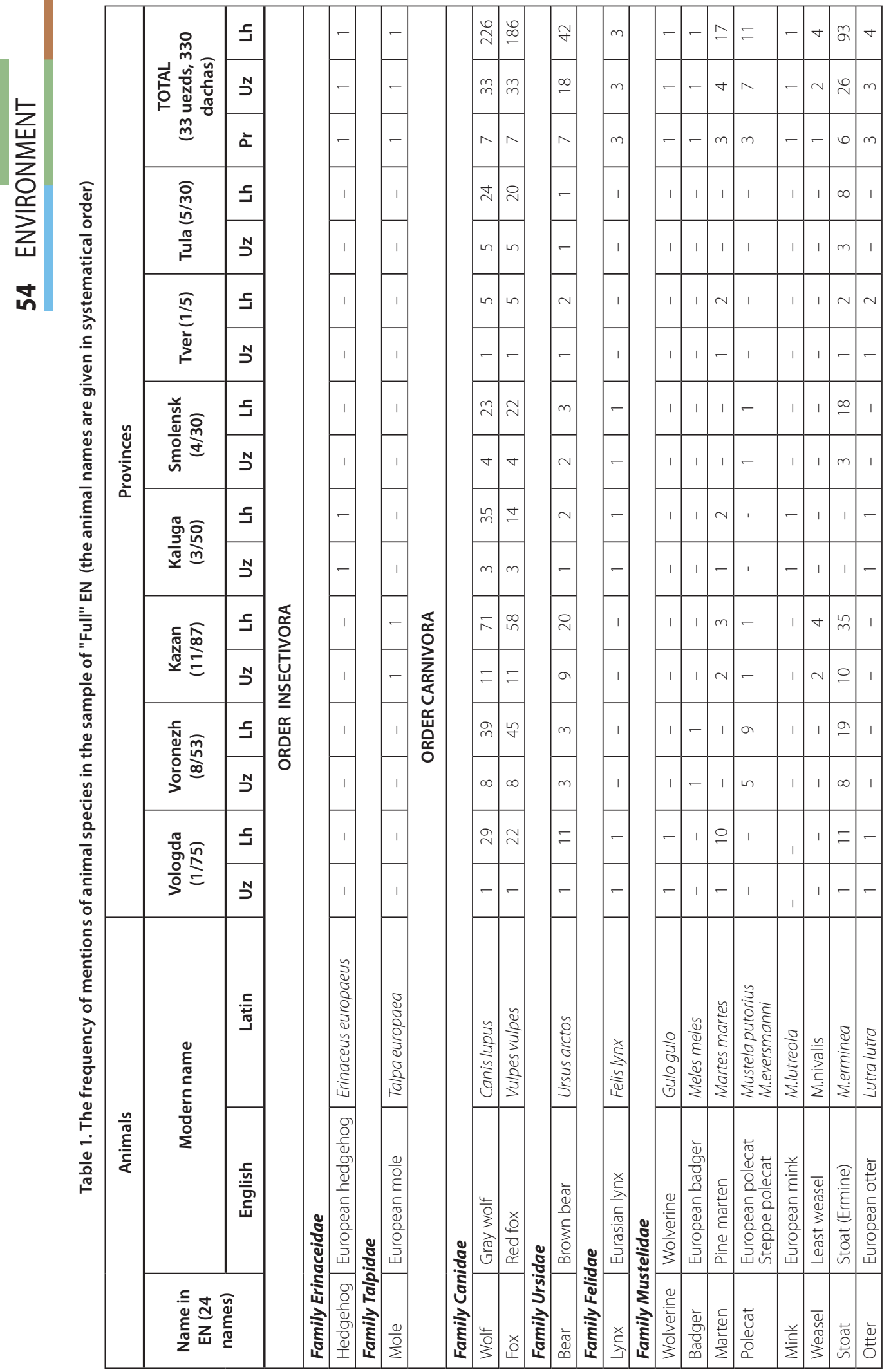




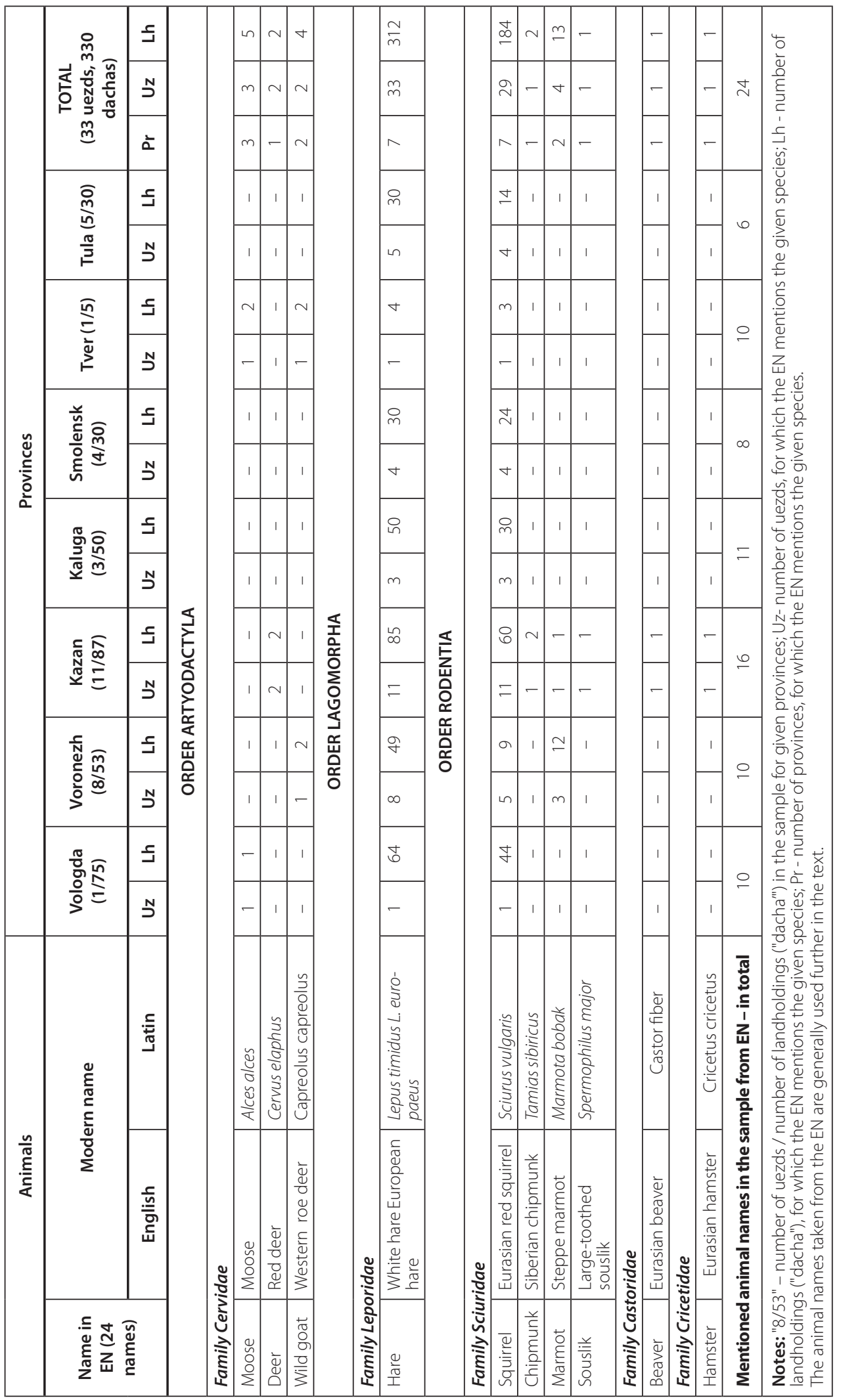




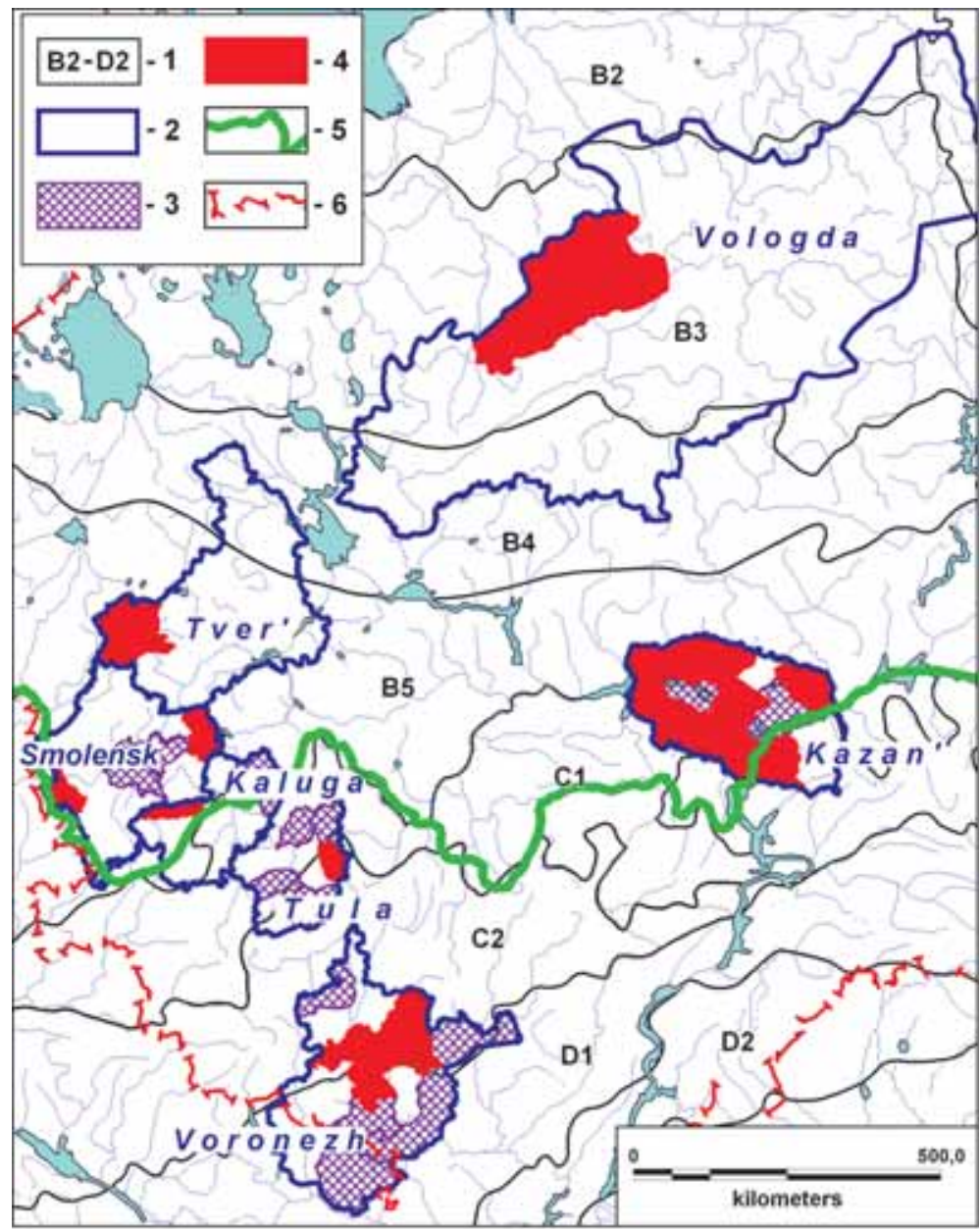

Fig. 3. The distribution of brown bear in the sample.

1 - Vegetation zones and subzones (see Fig. 1). 2 - Borders of provinces included in the sample.

3 - Uezds included in the sample. 4 - Uezds, for which the presence of bear is marked.

5 - Approximate modern position of the southern border of the bear distribution. 6 -Modern border of Russia

The frequency of occurrence of certain animals in the EN can presumably be explained by the following factors.

1. Significance for humans. The animal might be a hunting resource, a pest for agriculture, etc.

2. Visibility. Most animals are quite concealed, and many of them, even quite ordinary ones, are rarely observes by the humans. On the other hand, the notable animals may be mentioned, even having no economic significance.

3. The link with the specific phenological milestones in the life of nature (for example, certain species may be important for the "peasant calendar". This criterion is more important for birds, possibly, for some mammals, too.

Let us consider the species listed in the sample, starting from the most frequently mentioned (see Fig. 2).

The absolute leaders is hare (312 references in 330 dachas). We should remember, however, that we are talking about two species white hare and European hare, not separated in the EN (see Table 1). White hare is a species of taiga and tundra and, accordingly, originally inhabited the northern part of the 
region. European hare tends to open spaces and originally dwelt in its southern part. Now in the vast territories of the ETR, they live together, dividing the territory biotopically: white hare in the forest areas, European hare in the fields. It is likely that the same situation could have occurred in the times of the GLS in the forest-steppe zone (see Fig. 1) where the hybrids of these species popularly called "tumak" have been known for a long time. Hares fully meet the criteria of relevance and visibility. As the object of hunting, they always attracted attention, and they could be trapped, without the use of remote weapons, which is important for the peasants. Hares are pests of a number of vegetable and horticultural crops to the present day. The role of hares in the life of the Russian peasants is widely reflected in the literature and folklore. Therefore, the high number of references in the $\mathrm{EN}$ is quite natural.

Next are wolf (226), fox (186), and squirrel (184). Their high statistics does not raise any questions also. Up to the present day, they live almost throughout the entire ETR; the number of wolves is obviously much smaller today than in the period of the GLS, but foxes are common, and sometimes numerous.

Wolf is a traditional object of hunting, a serious threat for cattle breeding, and, in the past, a real danger to humans. It can rarely be observed, but in the areas of habitation, it is often heard (howling). Fox is, too, important for hunting, and a well-known threat for the poultry. It is more noticeable than wolf, and is often observed near human habitation. Fox, at the time, was the main reservoir of the most dangerous infections rabies. The infected foxes interacted with domestic dogs that could pass the disease to humans, and represented a real danger in the XVIII century, when medicine was nearly powerless against rabies.

Squirrel is noticeable and economically important. In the Soviet Union, it held the leading position in the fur production (regarding the number of pelts, but not their value). Of course, squirrel was an object of hunting at the time of the GLS, and, as in the case of hare, mainly by traps, making this resource potentially accessible to everyone.

The high frequency of mentions of stoat (93) presents some interest. Stoat lives almost everywhere in the ETR, but are not too numerous and noticeable. In the past, it was a valuable fur resource - as a "royal" fur used for the mantles of monarchs. But it is doubtful whether its production was widespread. On the other hand, weasel (4), is mentioned very rarely, although it is distributed as widely as stoat and is more numerous. These animals look alike, both in summer and winter; the most clearly visible difference is black "brush" (terminal hair) of the stoat's tail, which weasel does not have. Weasel, which is not a fur resource, is known as a malignant pest of poultry. Sightings of this animal should have been much more frequent than those of stoats.

Bear (42). As it was said earlier, brown bear is the only specie referred in the sample, for which we have the observations of the GLS located far enough outside the current range (see Fig. 3). Bear is mentioned in one uezd of the Tula province and, what is particularly interesting, in three uezds of the Voronezh province. These territories lie within the forest-steppes and northern steppes, while bear needs large forest areas for the stable existence of its population. It was noted earlier that the range of bear in the past reached the steppes [Dinets, Rothschild, 1996, etc.]. Today in Voronezh region, there are two State Nature Reserves Voronezhsky and Khopersky that include mainly the forest ecosystems. But there is no bear even in these large protected forest areas [Reserves ..., 1989].

The particular attention of the surveyors to bear can be easily explained. Although its practical importance for the population was hardly very significant, bear was (and remains) one of the most well known animals. It can be assumed that the presence of bear in the three uezds of the Voronezh 
province was connected with the fact that vast woodlands were preserved there, considered as protected in the XVII - early $\mathrm{XVIII}$ centuries. Anyway, it is obvious that this question deserves a special study.

The group of animals with the average frequency of occurrence (see Fig. 2) includes martens (17), marmots (13), and polecats (11),

Marten was once an important object of the fur trade, but by the time of the GLS, its economic significance in the major part of ETP was probably lost. These animals are not very cautious, nor do they present any threat for the peasant economy. Perhaps, marten was mentioned in the regions where they still retain some commercial value. All these mentions are within the modern range of the species.

Marmot (steppe marmot, or bajbak), on the contrary, is extremely noticeable, both the animals themselves, and the traces of their activity (holes, etc.). Marmot, in the period of the GLS, was probably not of great practical importance for the humans, as it neither caused any significant damage to agriculture, nor could be systematically hunted [Bibikov, Rumiantsev, 1997]. However, the surveyors apparently could not but mention marmots, where they lived, due to their cautioness. In addition, marmot is one of the few animals that meet the "phenological" criteria mentioned above. Seasonal events in the life of marmot (in spring, it comes out of holes and makes "the first whistle" and in autumn, it starts hibernation) could serve as important indicators of certain natural phenomena for the rural population. In the sample, marmot is mentioned in all the territories where they could live at the time and where they live today.

Polecat. As with hare, two species are called by this name in the GLS materials - European (black, dark) and steppe (light) polecat. Their areas correspond to their names and, in the forest-steppe belt, they can live in one area, but in different biotopes. Not being an object of hunting, they were (and are) some of the worst pests of poultry. Getting into a coop, the polecat often kills all the birds, although it obviously cannot eat them. The attention of the GLS respondents to polecat is quite understandable, and they are mentioned in the same areas where they are common today.

Of particular interest are the animals, now common in specific areas, often significant, but very rarely mentioned in the EN. This category includes 15 names (see Table 1, Fig. 2). First, for some of them, the low frequency of mentioning is understandable. These are hedgehog and mole. It is hard to imagine a peasant who does not know these animals. But on the other hand, they were, apparently, considered to be self-evident, and not deserving special attention.

We have already discussed weasel. Otter and mink, although they are quite widespread valuable fur-bearing animals, are not numerous and are very rarely seen by the people who have no special interest in hunting them.

Lynx, wolverine, and chipmunk are taiga animals, although lynx (see above) can penetrate quite far to the south. All of them have no discernible economic value in the ETR. Wolverine in the sample (see Table 1) is mentioned only in the territories where it lives in the present. Chipmunk is mentioned only in the Kazan province (see Table 1); today, they penetrate farther to the west, and may be encountered in many taiga areas of the ETR.

Souslik and hamster. Judging by the localization of the only reference (the Kazan province), we are talking about large-toothed souslik and Eurasian hamster. They are quite common in the areas noted in the sample. Souslik originally lived on the left-bank of the Volga river, but now, it penetrated into the right bank of the Volga. Hamster originally dwelt almost everywhere in the steppe and forest-steppe zones of European Russia, but now spread far to the north in the forest zone. Both of these species can cause 
some damage to agriculture, but are not numerous and are not objects of hunting. Therefore, their absence in the EN materials is understandable. But why is speckled souslik (Spermophilus suslicus) not mentioned? It is very widely found in the steppe and forest steppe zones (to the Volga river), in the Voronezh province, and to the south of the Tula province within the borders of the sample. This specie is detrimental to the crops much more than those mentioned above, and very noticeable. But there are no mentions of the specie in the sample.

Bardger is widespread, although not very visible. They are objects of hunting (the badger fat is widely used in the traditional medicine). They are mentioned only once (in the Voronezh region), which is difficult to explain.

Beaver. Eurasian beaver, since ancient times, was one of the most important fur-bearing animals of Russia. The value of fur and the relative ease of hunting resulted in almost complete disappearance of beaver on the ETR, but in recent decades, it again becomes common and even numerous everywhere where suitable conditions exist. In the sample, it is mentioned once in the Kazan province, despite the obvious importance and high visibility. The sample includes the territories, where in the XX century, beaver was there even during the peak period of depression (the Voronezh region); the EN does not mention it, however. It can be assumed, that by the GLS period, the number of beaver in the EPR has decreased so dramatically, that almost everywhere "only toponyms remained" (quite common in the ETR).

Artiodactyl is mentioned in the sample very rarely: deer (2), moos (5), and wild goat (4).

Deer (red deer) is extremely rare at the ETR today. They are animals of deciduous forests, now nearly lost in the study area, at least, in the areas, sufficient for the existence of stable populations of deer. In addition, in the XX century, sika deer (Cervus nippon) was introduced from the Far East, making a strong competition for the aboriginal species. Supposedly, deer was extremely rare in the times of the GLS, too, but in the Kazan province, where it is mentioned by the EN, it lives even now.

Moose originally inhabited nearly the entire forest and forest-steppe zones of Russia, and from the middle of the XX century, due to the intensive planting of forest belts, have moved far to the south. Today, it is common, even in densely populated areas of the European part of Russia, and one of the main objects of sports hunting. In the period of the GLS, moose was probably equally common in forests, although its importance for the population is difficult to assess. Moose still lives in all the territories where it was recorded in the sample; it is somewhat surprising, however, that the mentions are rare or even absent in some instances (for example, in the Smolensk province).

The term "wild goat" supposedly means western roe deer in the EN. The other contenders for this title are not present in the wildlife of the ETR. The natural optimum of roe deer habitats lies in the forest-steppe subzone, but today, the area extends to the north and south. Roe deer is also one of the most important objects of sport hunting. It is more visible than moose, though we can not assess its relevance to the population during the GLS. In the sample, the mentions of deer are associated with the Voronezh and Tver provinces. It is not clear why there is no mentions in, for instance, the Kaluga and Tula provinces, where it is now quite common.

And finally, the animals, generally not mentioned in the sample. Based on the total number of modern mammal species in the ETR (see above), they are much more numerous, than those mentioned. For the vast majority of such species the explanation of this fact is quite obvious.

The mammalian fauna of the ETR (and Russia as a whole, and other areas) is much more 
than 50\% formed by the species belonging to the category of having no taxonomic status, and traditionally, although quite arbitrary, are called "Small mammals Micromammalia." These include (in the ETR) the following groups of animals:

- In the insectivorous - shrew (Soricidae).

- In the rodents - so-called "mouse-like rodents". There are actually mouse, rat, birch mouse, dormouse, vole, small hamster, etc. (the Latin names of the groups are not shown).

\section{- All the bats (Chiroptera).}

The reasons for the lack of references to the animals in this category are easy to explain. Sometimes, their presence is selfevident; sometimes, they do not deserve the attention; and sometimes, both. It should be taken into account that even today, a rare non-specialist knows the differences between mouse, vole, and birch mouse. Bat, among the mammals are so aloof, that the question arises, if they were supposed to be animals at the times of the GLS. (что вы хотели сказать? [они были, конечно же представителями животного мира?] но жили ли тогда?)

Certain species of this category could be mentioned in the EN, for example, garden dormouse (Eliomys quercinus), greater mole rat (Spalax microphtalmus), and some others. Dormouse is quite common in most of the areas covered by the sample and, today, often causes considerable damage to fruit crops. Mole rat is widely distributed in northern steppes and forest-steppes of the ETR. Although the animal itself is almost impossible to observe, the traces of its life (soil emissions - что здесь имеется в виду?) are extremely noticeable. In addition, mole rat can cause significant damage to truck crops - especially root. In any case, these animals are well known for the contemporary rural population of the territories. However, the lack of mentions of these species in not surprising.
There are very few species left, that could or should be mentioned in the EN, but such mentions are not found in the sample. We have already discussed the case of speckled souslik (see above). In addition, wild boar (Sus scrofa), Russian desman (Desmana moschata) and European bison (Bison bonasus) should be mentioned.

Wild boar is now common in almost all the ETR, except for the northern regions. But originally it was spread far west of this area. Active natural expansion of boar to the east and northeast began in the XX century and continues to this day. This process is traced in detail in the literature [Bobrov et al, 2008, etc.]. At the time of the GLS, boar did not inhabit the territories covered by the sample.

Russian desman is a valuable fur-bearing animal; it originally dwelt only in the ETR (west of the Volga river), but during the XIX and early XX centuries, its number and area have drastically decreased, both because of uncontrolled hunting and deterioration of the environment (pollution of rivers and lakes leading to the deterioration of food resources). In the XX century in the Soviet Union, extensive work was carried out to restore desman in the areas of former habitat and to advance its area beyond. As a result, the modern area of desman is noticeably larger than the original, but in general, it is still quite rare. In the period of the GLS, desman could still be quite common in some territories covered by the sample. This animal can not be considered prominent, but where the desman population was sufficient, it was almost certainly an object of hunting. Accidentally, desman could be observed in different situations too, for example, it could get in fishing nets. However, it is not mentioned in the sample.

European bison in the distant times inhabited almost the entire middle belt and the south of European Russia. However, by the time of the GLS, it was, apparently, completely extinct, although there are indications of its presence in the XVIII century within the territory of the Voronezh province [Bobrov et 
al., 2008, etc.]. Currently, wild European bison is not found anywhere. Due to the efforts to restore the specie, the semi-wild populations exist in a number of reserves.

\section{CONCLUSION}

24 names ( 26 species) of mammals are found in the studied sample. They are mentioned at different rates - from very high to a single mention. This, apparently, is determined by two main factors, namely, the importance of animals to the humans and their visibility. Nearly all the species that could attract the attention of the surveyors are mentioned.

The analysis revealed that all the species mentioned in the sample inhabit the corresponding territories and today, and many of them are quite common or even numerous. Almost all the locations of animals found in the sample are within their current ranges. No specie has disappeared from the ETR.

At some territories included in the sample, certain significant and noticeable species are present, not mentioned in the EN either generally or for those specific areas. This may be due either to the natural expansion of the areas of some species (wild boar, moose, chipmunk, etc.) or due to the human activities on their breeding widely conducted in the XX century. For example, at least 4 mammal species, intentionally imported from other regions of Russia or from abroad live in the ETR today.

In some cases, it is hard to give an unambiguous explanation to the low frequency of mentions or even to its absence. Perhaps, this is due to the insufficient sample size at the province level. However, one should take into account the fact that the real state of the mammals in the period of the GLS is generally very poorly known.

Thus, our analysis leads to the main conclusion, which directly opposes the prevailing (as noted above) ideas about the reduction of the abundance of the ETR fauna since the end of the XVIII century. The faunal diversity in the study area is much greater today than in the time of the GLS, at least for mammals, both for the entire ETP and for specific regions. Of course, certain species could have disappeared from certain locations, but the sources do not allow us to observe these changes.

For an environmentalist, the explanation of this fact is quite obvious. The postulated depletion of the fauna is usually associated with the agricultural development of the territories and the accompanying deforestation. But for animals, this factor is rather positive than negative. The species, requiring the large continuous forests, are rare in the ETR (brown bear). The majority of the species are most comfortable within a highly mosaic territory, i.e., when forest and open areas alternate. Some species (e.g., roe deer) are inherently "marge" animals. Initially, these biotypes were forest-steppe, but, now, they have extended far to the north. Agriculture also offers many new kinds of food, nutritious and plentiful. On the other hand, the field-protective afforestation actively carried out in the south of the study area in the middle of the XX century, has created the conditions for the expansion of the forest species (such as moose) to the south. As a result, today in the ETP, we can observe a mix of southern and northern faunas, which greatly improves the overall faunal diversity.

In addition, in the XX century, one more important factor came into effect, specifically, the governmental programs for conservation, restoration, and enrichment of Russian (USSR) fauna. Their result was the revival of many species disappeared completely (zubr) or almost completely (muskrat, beaver, marmot, and others), as well as the introduction of new species. Now, the Central regions of the ETR by the diversity of terrestrial vertebrates occupy one of the leading places in Russia - along with some districts in southern Siberia and the southern Far East [Rumiantsev, Danilenko, 2007]. 


\section{ACKNOWLEDGEMENTS}

The research is supported by the RFBR, project 12-06-33035. The authors express their gratitude to A.Yu. Arutunov,
A.A. Bogomazova, M.V. Khatskevich, and V.D. Zhukov who participated in the archival research and compiling of the database.

\section{REFERENCES}

1. Bibikov D.I., Rumiantsev V.Yu. (1997). Current and past relations between people and marmots in the countries of the former Soviet Union // Informations of the National Academy of Sciences and Arts of the Chuvash Republic. No. 2, pp. 93-104 (In Russian).

2. Bobrov V.V., Warshavsky A.A., Khlyap L.A. (2008). Alien mammals in the ecosystems of Russia. Moscow: KMK Scientific Press Ltd., 232 p. (In Russian).

3. Danilenko A.K., Rumiantsev V.Yu. (2008). Mapping of terrestrial vertebrate communities based on geoinformation technologies // Biogeography in Moscow University. 60 years of the Department of Biogeography. - Moscow: GEOS, pp. 119-133 (In Russian).

4. Dinets V.L., Rotshild E.V. (1996). Animals. The encyclopedia of a nature of Russia. Moscow: ABF, 344 p. (In Russian).

5. Extinctions and Invasions: A Social History of British Fauna (2010). / Ed. by T. O'Connor, N. Sykes. London.

6. Golubinsky A.A., Khitrov D.A., Chernenko D.A. (2011). The materials of the General Land Survey: The potential of aggregation and analysis // Journal of Moscow University, Series 8, History. No. 3, pp. 35-51 (In Russian).

7. Kirikov S.V. (1959). Modifications of the wildlife in natural zones of the USSR (XIII-XIX c.). Steppe zone and forest-steppes. Moscow: Izd-vo AS of USSR, 173 p. (In Russian).

8. Kirikov S.V. (1966). Hunting wildlife, environment, and people. Moscow: Nauka, 348 p. (In Russian).

9. Kluchevskii V.O. (1987). Collected works. Vol. 1. Moscow (In Russian).

10. Lubavskii M.K. (1996). The Overview of the History of Russian Colonization. Moscow (In Russian).

11. Milov L.V. (1960). The "reports" of the poverennye peasants as a source for the Economic Notes of the General Land Survey // Archaeography yearbook. 1959. Moscow (In Russian).

12. Milov L.V. (1965). Research on "Ecomonic Notes" to the "General Land Survey" Moscow (In Russian).

13. Milov L.V. (2006). The Ploughman of Great Russia and the Characteristics of Russian Historical Process. 2 ed. Moscow (In Russian).

14. Ouchley K. (2010). Flora and Fauna of the Civil War: An Environmental Reference Guide. Louisiana City. 
15. Rackham O. (2001). The History of the Countryside: The Classic History of Britain's Landscape, Flora and Fauna. Camb. (???)

16. Reserves in the USSR. Reserves of European Russia. Part II (1989). / V.E. Sokolov and E.E. Syroechkovsky Eds. - Moscow: Mysl, 301 p. (In Russian).

17. Rumiantsev V.Yu., Danilenko A.K. (1998). The Information System "The communities of terrestrial vertebrates of Russia" // Problems of ecoinformatics. The 3rd international symposium. Moscow, pp. 126-129 (In Russian).

18. Rumiantsev V.Yu., Danilenko A.K. (2007). Species diversity of terrestrial vertebrates. Map 1:40000000 // National Atlas of Russia (4 chapters). Chapter 2. Environment (Nature). Ecology. Moscow: Roskartographia, p. 364 (In Russian).

19. Vegetation zones and types of vegetation belts in Russia and adjacent territories (1992). Map (1:8000000) / Ed. by G.N. Ogureeva. M.: Izd-vo LLP "Ecor" (In Russian).

20. Vodarskii Ja.E. (1988). Nobles Landholding in Russia, XVII - early XIX c. Moscow. (In Russian).

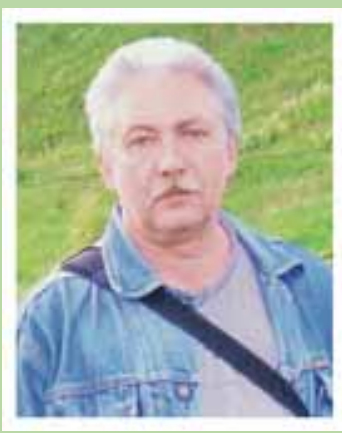

Vadim Yu. Rumiantsev has a PhD in Geography. He is Senior Researcher at the Department of Biogeography, Faculty of Geography, Lomonosov Moscow State University. His main research interests include mammalian environmental geography, biogeographic mapping, and the use of GIS technology in biogeography. His current main scientific activities are in the field of theoretical, methodological, and practical aspects of geoinformation mapping of the distribution of terrestrial vertebrates. He is the author and a co-author of 230 scientific publications, including more than 80 thematic map-sheets in complex national and regional atlases.

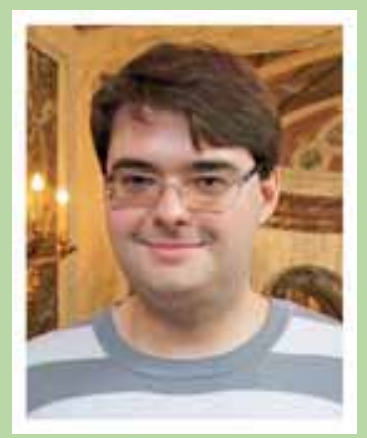

Alexey A. Golubinsky has a PhD in History. He is Specialist at the Russian State Archive of Ancient Documents (RSAAD), Moscow, Russia. Main objects of his scientific interests are: General Land Survey, peasant literacy, quantitative history. He published over 20 scientific papers. 


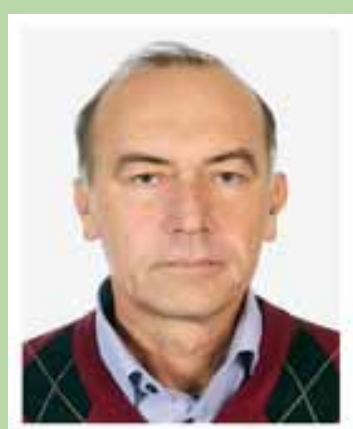

Mikhail S. Soldatov has a PhD in Geography. He is Senior Researcher at the Department of Biogeography, Faculty of Geography, Lomonosov Moscow State University. His scientific interests include a broad range of aspects of botanical geography, biogeographic mapping, and medical geography. He published 80 scientific papers.

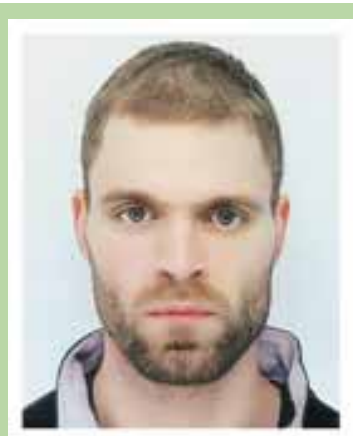

Alexandre Husson studied in Strasbourg University (MA in History, 2011). Now, he is a doctoral student at Paris I PanthŭonSorbonne.

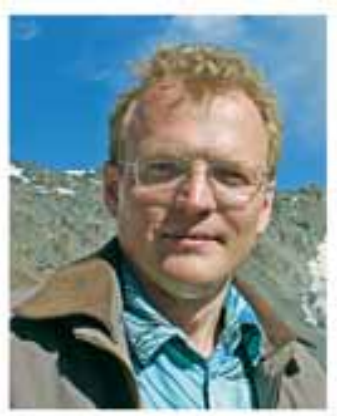

Dmitry A. Khitrov has a PhD in History. He is Associate Professor at the Department of Russian History to the beginning of XIX century, Faculty of History, Lomonosov Moscow State University, specializing in the social and economic history of Russia in XVII$\mathrm{XVIII}$ centuries. He is Executive Secretary of the Board of the 'Milovskie Chtenia' congress, one of the largest and most influential scientific forums on Russian history of the early modern period, a member of the Board of the Agrarian Symposium for the History of Eastern Europe. He is the author of 50 scientific publications. 